\title{
Constraints to Progress in Embryonic Stem Cells from Domestic Species
}

\author{
M. Muñoz • B. Trigal • I. Molina • C. Díez • \\ J. N. Caamaño • E. Gómez
}

Published online: 29 January 2009

(C) Humana Press 2009

\begin{abstract}
Domestic animal embryonic stem cells are of potentially big value in transgenic research and studies of lineage commitment and development. Unfortunately, despite many efforts, validated embryonic stem cell lines in species other than mice and primates are yet to be isolated. Here we review some factors that might help to explain why derivation of domestic animal embryonic stem cells is still unsuccessful.
\end{abstract}

Keywords Embryonic stem cells $\cdot$ Domestic species

Since the first embryonic stem cell lines isolation from mouse embryos in $1981[1,2]$ the number of published articles dealing with these unique cells has steadily increased (Fig. 1. Pubmed citations dated on January 1981- December 2008). The rise in the number of publications can be taken as a reflection of the interest aroused by these cells due to their unique biological properties and numerous applications.

Stem cells derived from early embryos (Embryonic Stem Cells; ESC) are cultured cell lines that can be clonally propagated and maintained in culture indefinitely, while their ability to differentiate in vitro or in vivo into derivatives of all three germ layers remains preserved. Thus, ESC can contribute to form all tissues and organs, including germ cells. These singular traits have made ESC a useful tool for studying mammalian development, nuclear reprogramming, and cell lineage commitment and differentiation.

M. Muñoz $(\bowtie) \cdot$ B. Trigal $\cdot$ I. Molina $\cdot$ C. Díez $\cdot$ J. N. Caamaño

E. Gómez

Área de Genética y Reproducción. SERIDA,

Camino de los Claveles 604,

33203 Gijón, Asturias, Spain

e-mail: mmunoz@serida.org
Manipulation of ESC by homologous recombination is highly efficient [3], which provides a route for the precise modification of the animal genome by gene targeting. Currently, genetically modified mice are routinely produced by embryonic stem cell technology [4]. Transgenic mice are essential tools in the understanding of functional genomics, mammalian physiology and as animal models for a number of human diseases.

Several animal reproductive biology research initiatives have envisaged the production of gene-targeted farm animals for improving productive traits and disease resistance and as models for human diseases. Such farm species would not show some of the limitations of the mouse model i.e. short life span or a physiology and anatomy very different from humans. Unfortunately, contrary to mice and primates, a key barrier to genetic modification in livestock has been the failure to establish embryonic stem cell lines from domestic species, which remains as a multi-faceted challenge. As pointed-out within several recent reviews [59], progress in ESC will arise from research focusing on the understanding of species-specific mechanisms that maintain pluripotency; identification of appropriate stem cell markers; and optimization of culture conditions.

The existence of significant morphological and functional similarities between ESC from very different species $[10,11]$ might have led researchers to an inappropriate, direct application on farm species of specific conditions used to isolate and maintain ESC from mice and humans. As a result of this misconception, and provided that important differences have also been observed [11], we need to make stronger research efforts on specific traits of domestic animal ESC. This way, it will be possible to remove limitations hampering the progress of embryonic stem cell technology in domestic species. Some of the above cited differences, and therefore major research 


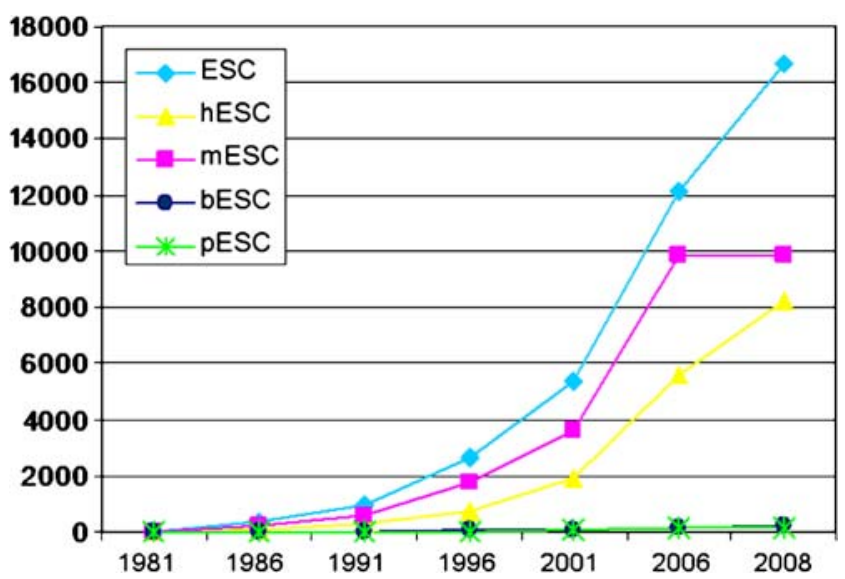

Fig. 1 Cumulative numbers of Pubmed citations dated on January 1981December 2008. Embryonic stem cells (ESC), - mouse ESC, $\Delta$ human ESC, $\bullet$ bovine $\mathrm{ESC},+$ porcine ESC

objectives regarding to domestic animal embryonic stem cell technology, are exposed in the present review.

\section{Mechanisms Underlying the Formation of Pluripotent Cell Populations}

The primitive ectoderm or epiblast is the source of ESC in mice [12]. The epiblast is defined by two segregation events that give rise to three distinct cell lineages: the trophectoderm, the primitive endoderm and the epiblast. The early lineage formation in the blastocyst is a common trait within all eutherian mammals. However, speciesspecific differences in the underlying mechanisms have been described. In mice, mutual repression of Oct-4 and $\mathrm{Cdx}-2$ at the early morula stage gives rise to the segregation of the two first cell lineages: the inner cell mass (ICM) and the trophectoderm. Subsequently, the ICM divides into the epiblast and the primitive endoderm, owing to a differential/mosaic expression of Nanog and GATA- 6 in two cell subpopulations [13]. However, in cattle and pig blastocysts, Oct-4 expresses both in the inner cell mass and in the trophectoderm, which suggests that the specification of the ICM and the trophectoderm compartments has to be accomplished by an alternative mechanism to that described in mice (i.e. lost of Oct-4 expression) [14]. Moreover, in porcine, the commitment of the epiblast and the primitive endoderm can not rely on a differential expression of NANOG and GATA-6, as the former has not been detected in porcine blastocysts [13].

Up to now, it was commonly accepted that events during early embryonic development were similar between mammals. However, the broad amount of data starting to be gathered, underlines that differences in early lineage segregation do exist, which might influence the character- istics of the pluripotent cell population formed [13]. Clearly there is a need for more global transcriptomic and proteomic studies across species at the relevant stages of development. Such approaches will lead to a full knowledge of molecular pathways that control blastocyst lineage development. The information gained with these studies would allow to get know-how to develop stem cells from different species.

\section{Species-Specific Pluripotency Markers}

The above cited specificity of mechanisms responsible for early lineage commitment makes it difficult to transfer knowledge between species. Thus, creating proper procedures to isolate ESC and search for appropriate markers are a must when dealing with new species. Until now, the identification and characterization of domestic animal ESC was mainly based on morphological criteria and transposition of classic mESC and hESC markers, such as stage specific embryonic antigens (SSEA-1, -3, -4) and Oct-4. These markers unequivocally identify stem cells in mice and primates, as their expression is confined to pluripotent cell populations, i.e. the inner cell mass of the blastocyst and embryo-derived cell lines $[15,16]$. However, in ungulates, these markers are expressed both within the inner cell mass and the trophectoderm (Fig. 2); therefore their use as single markers might be inappropriate to identify ungulate ESC [17].

It has been suggested that in late implanting species, such as porcine or bovine, continued expression of epiblast specifying genes in trophectoderm cells concomitant with transcription of trophectoderm-specific genes, allows elongation and prevents premature differentiation of the trophectoderm [18]. These "intermediate" transitory cell

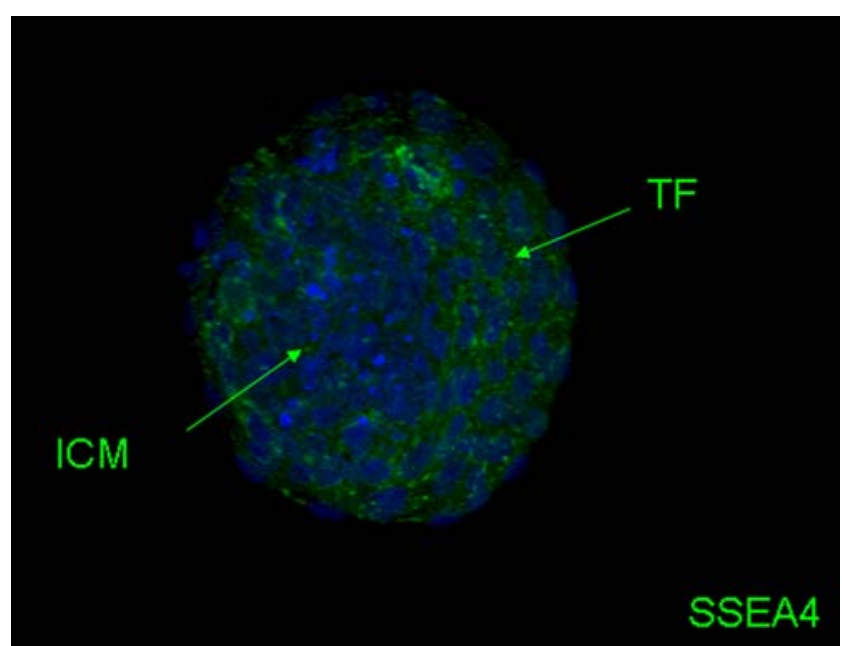

Fig. 2 Overlay of stage specific embryonic antigens SSEA-4 with DNA stain in bovine blastocyst 
types seem to co-express both features of undifferentiated stem cells and their differentiated derivatives. Therefore, the use of human and mice pluripotency markers on ESC from other species should be inappropriate without an exhaustive knowledge of the behaviour of such markers during early embryonic development, which to our thought has not been assessed yet. As the expression of such markers is not limited to the ICM, it may lead researchers into artefacts at the time to accomplish ESC derivation and culture.

\section{Pluripotency Maintaining Factors and Cell Culture Conditions}

Attempts to set up domestic animal embryonic stem cell lines may have been unsuccessful in part due to the inability to develop suitable culture systems for these species. The most frequently used culture conditions for farm animals ESC are based on mESC cultures, which were used firstly to derive hESC $[1,2,19]$. This way, domestic animal ESC have usually been co-cultured on a feeder layer, often mouse embryonic fibroblasts, while culture media were supplemented with nutrients and growth factors found to be involved in the maintenance of $\mathrm{mESC}$ and hESC pluripotency.

Unfortunately, it is likely that culture conditions suitable to support mouse and human ESC are inadequate to maintain ESC in other mammalian species, which may differ in factors and cellular signalling cascades important for the maintenance of ESC pluripotency [6]. For example, BMP4, a member of the transforming growth factor- $\beta$ (TGF- $\beta$ ) family involved in controlling mESC differentia- tion, is not only dispensable in maintaining hESC pluripotency but is also detrimental as it induces differentiation of hESC into trophoblast cells [20].

The above statements have been confirmed by a recent cross-species transcriptional profiles of human and mouse ESC $[10,11]$. These studies established that although there appears to be a core set of ESC-specific pathways conserved across species, other divergent pathways are equally critical in ESC development (Fig. 3)

Thus the expression patterns of leukaemia inhibitory factor (LIF), fibroblast growth factor (FGF) and BMP4 pathways are not conserved between human and mouse ESC. Nevertheless, Nodal/Activin pathway showed a significant positive correlation between them. These results are consistent with the requirements of $\mathrm{mESC}$ for LIF and BMP4, whereas hESC needs the presence of FGF-2, to preserve their pluripotency in the absence of feeder cells. The conserved expression pattern of the Nodal/Activin pathway suggests that this pathway is fundamental to ESC pluripotency.

The on-going comparative transcriptomic studies of ESC across different species will hopefully identify more fundamental signal transduction pathways for ESC maintenance that will enable the design of optimal culture conditions for domestic animal ESC.

\section{Conclusions}

More than 20 years ago Betteridge and Fléchon [21] stated: "So much embryological information and teaching material is based on the extensive studies of early development in
Fig. 3 A selection of transcriptionally conserved and divergent pathways mediating pluripotency and differentiation of murine and human embryonic stem cells

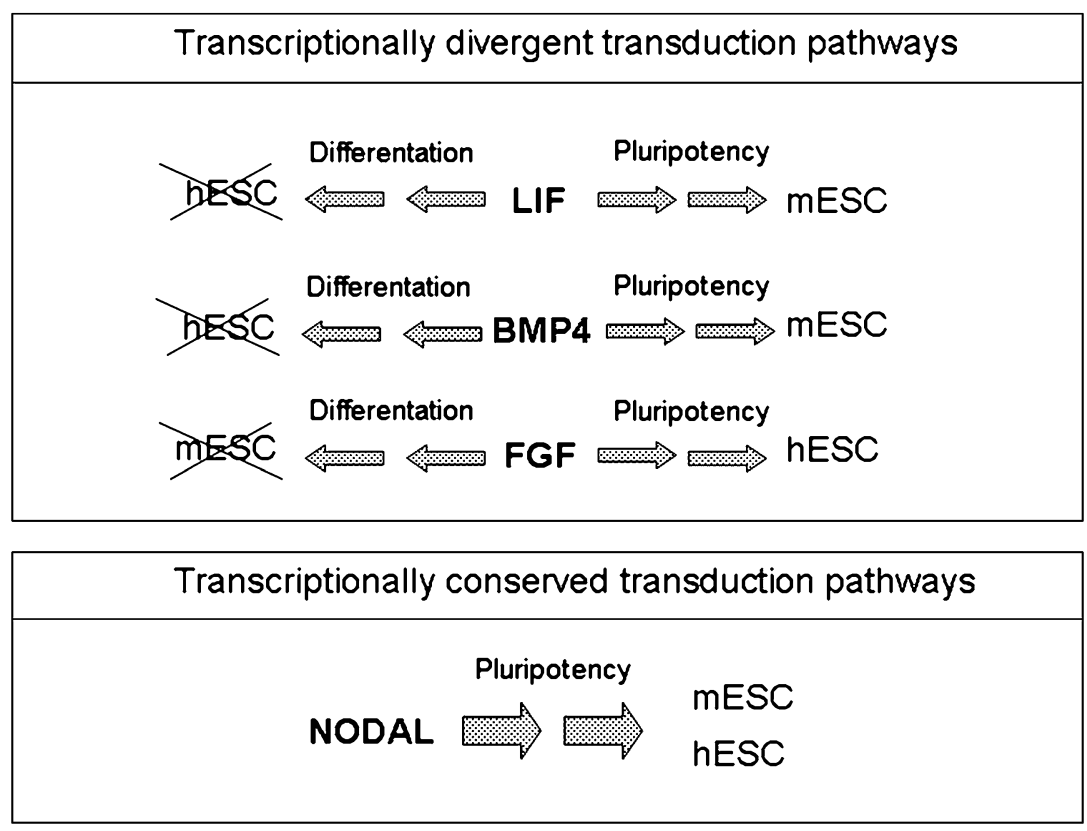


mice and humans that there is a real danger of being misled by consequent extrapolations and assumptions". Currently, a similar conclusion could be drawn from the comparative approach undertaken for the study of ESC: So much ESC data is based on the extensive studies of mice and humans that there is a real danger of being misled by subsequent extrapolations and assumptions.

Therefore if we want to succeed into isolation and maintenance of ESC lines from species other that human and mice, it is imperative that we perform careful crossspecies comparison without overlooking species-specific differences.

Acknowledgments Dr M. Muñoz and I. Molina are supported by grants from the Spanish Ministry of Science and Innovation.

B. Trigal is supported by a grant from the Caja de Ahorros of Asturias.

This work is supported by Spanish Ministry of Science and Innovation (Project AGL2005-04479)

\section{References}

1. Evans, M. J., \& Kaufman, M. H. (1981). Establishment in culture of pluripotent cells form mouse embryo. Nature, 292, 154-156. doi:10.1038/292154a0.

2. Martin, G. R. (1981). Isolation of a pluripotent cell line from early mouse embryos cultured in medium conditioned by teratocarcinoma stem cells. Proceedings of the National Academy of Sciences of the United States of America, 78(12), 7634-7638. doi:10.1073/pnas.78.12.7634.

3. Capecchi, M. R. (1989). Altering the genome by homologous recombination. Science, 244(4910), 1288-1292. doi:10.1126/ science. 2660260

4. Bradley, A. (1987). Production and analysis of chimaeric mice. In E. J. Robertson (Ed.), Teratocarcionomas and embryonic stem cells: A practical approach (pp. 113-151). Oxford: IRL.

5. Keefer, C. L., Pant, D., Blomberg, L., \& Talbot, N. C. (2007). Challenges and prospects for the establishment of embryonic stem cell lines of domestic ungulates. Animal Reproduction Science, 98, 147-168. doi:10.1016/j.anireprosci.2006.10.009.

6. Renard, J. P., Maruotti, J., Jouneau, A., \& Vignon, X. (2007). Nuclear reprogramming and pluripotency of embryonic cells: Application to the isolation of embryonic stem cells in farm animals. Theriogenology, 68(Suppl 1), S196-S205. doi:10.1016/j. theriogenology.2007.05.060.

7. Brevini, T. A., Antonini, S., Pennarossa, G., \& Gandolfi, F. (2008). Recent progress in embryonic stem cell research and its application in domestic species. Reproduction in Domestic Animals, 43(Suppl 2), 193-199. doi:10.1111/j.1439-0531.2008.01161.x.

8. Muñoz, M., Díez, C., Caamaño, J. N., Jouneau, A., Hue, I., \& Gómez, E. (2008). Embryonic stem cells in cattle. Reproduction in Domestic Animals, 43(Suppl 4), 32-37. doi:10.1111/j.14390531.2008.01229.x.

9. Talbot, N. C., \& Blomberg, L. A. (2008). The pursuit of ES cell lines of domesticated ungulates. Stem Cell Reviews, 4(3), 235254. doi:10.1007/s12015-008-9026-0.

10. Wei, C. L., Miura, T., Robson, P., Lim, S. K., Xu, X. Q., Lee, M. Y., et al. (2005). Transcriptome profiling of human and murine ESCs identifies divergent paths required to maintain the stem cell state. Stem Cells, 23(2), 166-85. doi:10.1634/stemcells.2004-0162.

11. Sun, Y., Li, H., Liu, Y., Shin, S., Mattson, M. P., Rao, M. S., et al. (2007). Cross-species transcriptional profiles establish a functional portrait of embryonic stem cells. Genomics, 89, 22-35. doi:10.1016/j.ygeno.2006.09.010.

12. Brook, F. A., \& Gardner, R. L. (1997). The origin and efficient derivation of embryonic stem cells in the mouse. Proceedings of the National Academy of the United States of America, 94(11), 5709-5712. doi:10.1073/pnas.94.11.5709.

13. Kuijk, E. W., Du Puy, L., Van Tol, H. T., Oei, C. H., Haagsman, H. P., Colenbrander, B., et al. (2008). Differences in early lineage segregation between mammals. Developmental Dynamics, 237(4), 918-927. doi:10.1002/dvdy.21480.

14. Kirchhof, N., Carnwath, J. W., Lemme, E., Anastassiadis, K., Schöler, H., \& Niemann, H. (2000). Expression pattern of Oct-4 in preimplantation embryos of different species. Biology of Reproduction, 63(6), 1698-1705.

15. Henderson, J. K., Draper, J. S., Baillie, H. S., Fishel, S., Thomson, J. A., Moore, H., et al. (2002). Preimplantation human embryos and embryonic stem cells show comparable expression of stagespecific embryonic antigens. Stem Cells, 20, 329-337. doi:10.1634/stemcells.20-4-329.

16. Nichols, J., Zevnik, B., Anastassiadis, K., Niwa, H., Klewe-Nebenius, D., Chambers, I., et al. (1998). Formation of pluripotent stem cells in the mammalian embryo depends on the POU transcription factor Oct4. Cell, 95(3), 379-391. doi:10.1016/S0092-8674(00)81769-9.

17. Muñoz, M., Rodriguez, A., De Frutos, C., Caamaño, J. N., Díez, C., Facal, N., et al. (2008). Convencional pluripotency markers are unspecific for bovine embryonic derived cell-lines. Theriogenology, 69(9), 1159-1164. doi:10.1016/j.theriogenology. 2008.02.014.

18. Degrelle, S. A., Campion, E., Cabau, C., Piumi, F., Reinaud, P., Richard, C., et al. (2005). Molecular evidence for a critical period in mural trophoblast development in bovine blastocysts. Developments in Biologicals, 288(2), 448-460. doi:10.1016/j.ydbio. 2005.09.043.

19. Thomson, J. A., Itskovitz-Eldor, J., Shapiro, S. S., Waknitz, M. A., Swiergiel, J. J., Marshall, V. S., et al. (1998). Embryonic stem cell lines derived from human blastocysts. Science, 282(5391), 1145-1147. Erratum in: Science 1998; 282. 5395 1827. doi:10. 1126/science.282.5391.1145.

20. Xu, R. H., Chen, X., Li, D. S., Li, R., Addicks, G. C., Glennon, C., et al. (2002). BMP4 initiates human embryonic stem cell differentiation to trophoblast. Nature Biotechnology, 20(12), 1261-1264. doi:10.1038/nbt761.

21. Betteridge, K. J., \& Fléchon, J. E. (1988). The anatomy and physiology of pre-attachment bovine embryos. Theriogenology, 29(1), 155-187. doi:10.1016/0093-691X(88)90038-6. 